\title{
REVIEW
}

\section{The unfolding stories of GPR30, a new membrane-bound estrogen receptor}

\author{
Marcello Maggiolini and Didier Picard ${ }^{1}$ \\ Department of Pharmaco-Biology, University of Calabria, 87030 Rende, Italy \\ ${ }^{1}$ Département de Biologie Cellulaire, Université de Genève, Sciences III, 30, quai Ernest-Ansermet, CH - 1211 Genève 4, Switzerland \\ (Correspondence should be addressed to M Maggiolini; Email: marcellomaggiolini@yahoo.it; D Picard; Email: didier.picard@unige.ch)
}

\begin{abstract}
Steroid hormones such as estrogens are known to signal through ligand-regulated transcription factors of the nuclear receptor superfamily. In addition, they elicit rapid nongenomic responses from membrane-associated receptors. One of these receptors belongs to an entirely different family of proteins. The G protein-coupled and seventransmembrane receptor, GPR 30, is now widely recognized as an estrogen receptor (ER), hence its official new acronym
\end{abstract}

GPER. It appears to mediate a wide range of responses to estrogen in a large variety of cell types. Its functions are clearly distinct from those of the classical nuclear ERs, although these pathways may overlap and interact in some cases. Here, we review the history of the discovery of this new ER, the evidence for the claim that it is an ER, its signal transduction, and its potential functions in physiology and disease.

Journal of Endocrinology (2010) 204, 105-114

\section{Discovery and history of GPR30}

In contrast to what some text books might have advocated, for a lot of hormones and receptors, there is no one-to-one relationship. The steroid hormone estrogen, represented by the most potent physiological estrogen $17 \beta$-estradiol $\left(\mathrm{E}_{2}\right)$, is no exception. Estrogens have a multitude of different molecular targets, including two well-characterized members of the nuclear receptor superfamily, the estrogen receptors (ER) $\alpha$ and $\beta$ (listed as ESR 1 and ESR2 in the HUGO \& MGI Databases) (Dahlman-Wright et al. 2006, Heldring et al. 2007). In turn, the latter and other molecular targets also respond to a more or less broad range of physiological and synthetic compounds. When the discovery of a second nuclear ER, ER $\beta$, was reported in 1996 (Kuiper et al. 1996), it did come as a big surprise because it was felt that there was no 'need' for yet another ER. The only known ER at the time, $\mathrm{ER} \alpha$, was then shown to mediate rapid nongenomic signaling responses as well (Migliaccio et al. 1996). With this, it seemed that all estrogen responses were covered. This might explain why the more recent discovery of GPR30 as a membrane-associated ER was (and to some extent still is) met with a lot of skepticism. The field has come a long way since its discovery (Carmeci et al. 1997), and there are several recent and authoritative reviews on it (Filardo et al. 2008, Prossnitz et al. 2008, Prossnitz \& Maggiolini 2009). The goal of this review is to present the recent advances of GPR30 research, while highlighting its diversity and complexity and discussing remaining controversies and knowledge gaps.

The history of the discovery of GPR30 is unusual. In hindsight, one of the first hints came from the observation that estrogen could stimulate adenylate cyclase activity and thus the production of CAMP in human MCF7 breast cancer cells (Aronica et al. 1994; Fig. 1). The authors concluded from the fact that ER $\alpha$-negative MDA-MB-231 breast cancer cells did not display this response that $\operatorname{ER}(\alpha)$ was the most likely mediator. What they could not yet know is that MCF7 cells express GPR30, whereas MDA-MB-231 cells do not. Indeed, GPR30 was finally cloned a few years later as a cDNA of a gene that is differentially expressed in MCF7 compared with MDA-MB-231 cells (Carmeci et al. 1997). Considering that the expression profiles of the two cell lines must differ by a large number of mRNAs, it is amazing that the GPR 30 cDNA came out of this screen as the only novel sequence. Be it as it may, the same authors, based on a survey of a limited number of breast carcinoma cell lines and biopsies, concluded that GPR30 expression correlates with $\mathrm{ER}(\alpha)$ expression. More recent analyses with a larger number of samples clearly challenge this conclusion (Filardo et al. 2006, 2008). Again a few years later, Filardo et al. (2000) 


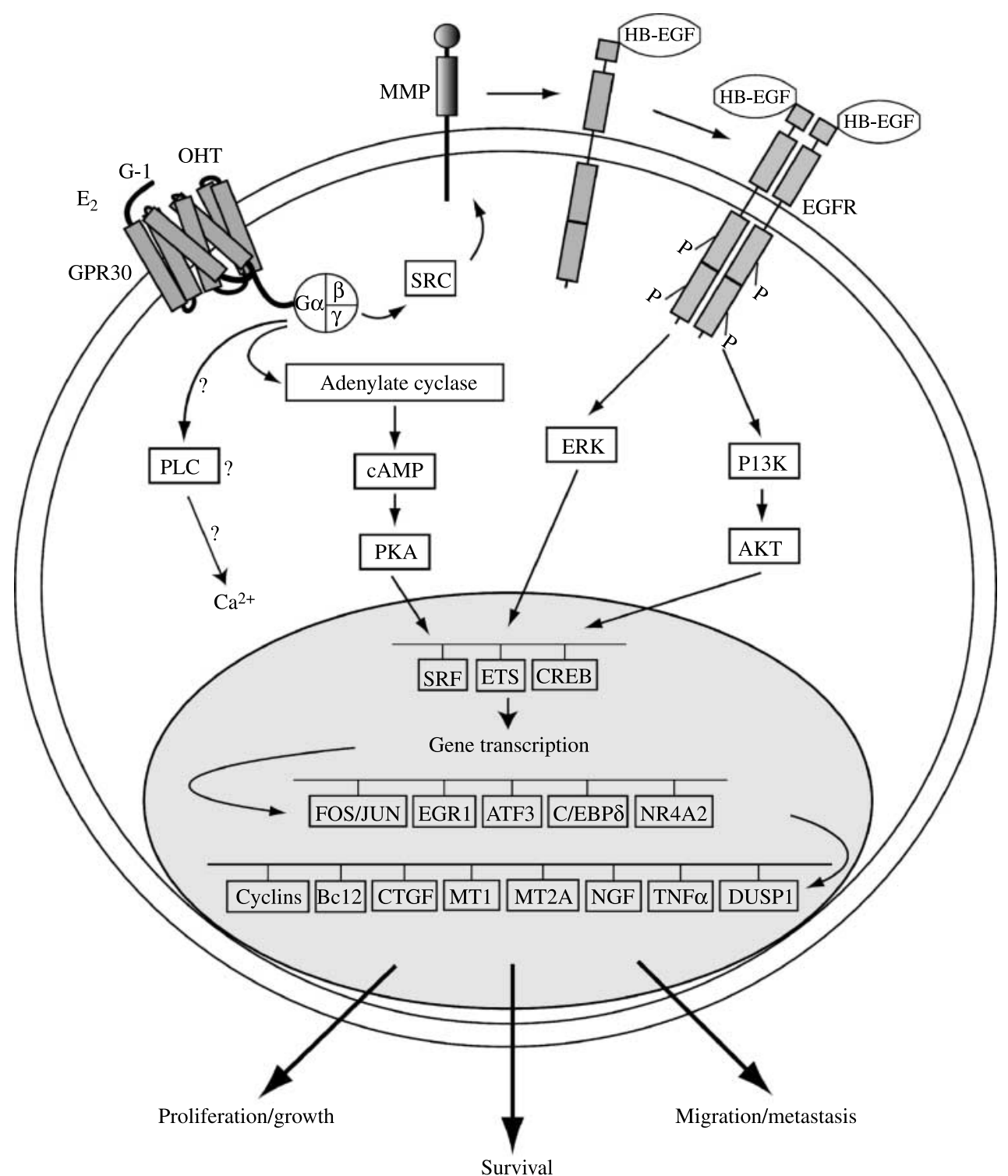

Figure 1 Schematic representation of the GPR30 signaling network. Abbreviations not mentioned in the text are: MMP, matrix metalloprotease; PLC, phospholipase C; PKA, protein kinase A. As pointed out in the text, the connections to an increase in calcium and those between the trimeric G-proteins and the PI3K-Akt pathway remain unclear. Note that we put GPR30 somewhat arbitrarily at the plasma membrane, but signaling would presumably largely work the same way with GPR30 at the membrane of the endoplasmic reticulum. Most target genes shown at the bottom are from Pandey et al. (2009).

showed that estrogen activates the mitogen-activated kinases (MAPK) Erk1/2 even in ER-negative SKBr3 cells. Unlike MDA-MB-231 cells, these were found to be GPR30 positive. A first convincing genetic case for GPR 30 as a novel ER was made by the demonstration that rapid estrogen responses could be transferred into nonresponsive MDA-MB-231 by transfection with a GPR30 expression vector (Filardo et al. 2002). Further genetic evidence came from experiments with keratinocytes in which GPR30 expression was blocked with antisense oligonucleotides (Kanda \& Watanabe 2004). These are some of the pioneering publications that ended up launching an entirely new field.

Upon the initial cloning of GPR30, the sequence immediately revealed that it is part of the huge family of G-protein coupled receptors spanning the membrane seven times (7TM-GPCRs). Within this family that comprises hundreds of members, it belongs to the class A rhodopsin-like ones and in there, it constitutes the chemokine receptor-like 2 
subfamily. With $28 \%$ sequence identity, it is most closely related to GPCRs such as the angiotensin II $1 \mathrm{~A}$ receptor and the interleukin $8 \mathrm{~A}$ receptor (28\% identity) (Carmeci et al. 1997, Feng \& Gregor 1997). These 'family ties' with GPCRs that bind peptide or protein ligands raises the intriguing question of whether GPR30 might also have such ligands, perhaps in addition to estrogens. A final word here about nomenclature: the protein that we will continue to refer to as GPR 30 in this review was cloned in parallel by several different groups and hence, got started with multiple different names, all in the same year (for example Bonini et al. 1997, Carmeci et al. 1997, Feng \& Gregor 1997, Takada et al. 1997). It should be noted that the rat ortholog was originally named GPR 41 (Bonini et al. 1997, Kimura et al. 2001), an unfortunate choice in view of the fact that there is an unrelated homonymous human GPCR. A decade later, now that GPR30 has been recognized as a membrane-bound $E R$, it has received a new official name: G-protein coupled ER1 (GPER).

\section{Signal transduction pathways}

Some of the very first reports already established that the GPCR GPR30 does indeed couple to G-proteins in breast cancer cells. Inhibitor studies and measurements of GTP recruitment to membranes revealed that both $\mathrm{G} \beta \gamma$ (Filardo et al. 2000) and a Gas (Thomas et al. 2005) may play a role in signaling. Downstream of $\mathrm{G}$-proteins, $\mathrm{E}_{2}$-induction leads to activation of a SRC-like tyrosine kinase, phosphorylation of the adaptor protein SHC, and, presumably through the activation of a metalloprotease, the extracellular release of heparan-bound epidermal growth factor (HB-EGF). A very recent publication indicates that integrin $\alpha 5 \beta 1$ acts as a conduit between SRC and metalloproteases (Quinn et al. 2009). Activation of SRC promotes the formation of SHC-integrin complexes and through these a fibronectin matrix assembly and metalloprotease activation. The release of HB-EGF allows it to activate the EGF receptor (EGFR) resulting in the induction of the MAPK pathway (Filardo et al. 2000; Fig. 1). The fact that $\mathrm{E}_{2}$ induces the production of cAMP has already been mentioned above. It could be linked to a GPR 30 response using membrane preparations of ER-negative SKBr3 cells as well as in whole cells transfected with GPR30 (Filardo et al. 2002, 2007, Thomas et al. 2005), and by a GPR30 antisense approach in keratinocytes and macrophages (Kanda \& Watanabe 2003a,b). It appears to be the Gas leg of G-protein signaling that is responsible for the $\mathrm{E}_{2}$ stimulation of adenylate cyclase and the ensuing increase in cAMP in breast cancer cells (Thomas et al. 2005). Similarly, a variety of phyto- and xenoestrogens are also able to stimulate cAMP production through GPR 30 (Thomas et al. 2005, Thomas \& Dong 2006). Somewhat paradoxically, the generation of cAMP attenuates MAPK activity via the inhibitory activity of protein kinase A on RAF1 (Filardo et al. 2002). It is likely that the exact balance between inhibition and stimulation of the MAPK pathway will depend on timing and cell type.
There are yet other early events. $\mathrm{E}_{2}$ activates phosphoinositide 3-kinases (PI3K) through GPR30. As a result of the accumulation of phosphatidylinositol 3,4,5-trisphosphate (PIP3), the anti-apoptotic and proliferative kinase AKT is activated. This follows its recruitment to membranes via its pleckstrin homology domain, a phenomenon that has been used as an elegant read-out of GPR30 signaling (Revankar et al. 2005). PI3K activation was further shown to be sensitive to the EGFR inhibitor AG1478 but insensitive to pertussis toxin. The latter suggests that the activation of PI3K, unlike that of a SRC-like kinase, is not downstream of G $\beta \gamma$. Using new GPR30-specific pharmacological tools, this was recently further substantiated (Dennis et al. 2009). The specific GPR 30 antagonist G15 (see also below) inhibited the stimulation of PI3K by both $\mathrm{E}_{2}$ and the specific GPR30 agonist G-1 (see below) in SKBr3 breast cancer cells, which endogenously express GPR 30. The stimulation of PIP3 production by $\mathrm{E}_{2}$ and $\mathrm{G}-1$, and their inhibition by $\mathrm{G} 15$, could also be demonstrated with GPR30 exogenously expressed in ER-negative COS7 cells. An increase in intracellular $\mathrm{Ca}^{2+}$ was shown to be a very rapid response to GPR 30 activation in different cell contexts (Revankar et al. 2005, Bologa et al. 2006, Filardo et al. 2007, Dennis et al. 2009). Similarly to other downstream events, this $\mathrm{E}_{2}$ response could be inhibited with the antagonist G15 (Dennis et al. 2009). Formally, it has not been determined what triggers the increase in calcium and where it comes from. Both a release from intracellular calcium stores and an influx from outside are possible. Phospholipase C appears not to be involved (Revankar $e t$ al. 2005), but this may depend on cell type or indicate that some other phospholipase is (Fig. 1). The details of some of the connections need to be further investigated.

While all of these signaling events happen within seconds and minutes, there is accumulating evidence that GPR 30 signaling triggers more long-term transcriptional responses (Prossnitz \& Maggiolini 2009). Kanda \& Watanabe established this link with macrophages and keratinocytes. The elevated levels of cAMP that GPR30 signaling triggers lead to the induced expression of $c$-fos in macrophages (Kanda \& Watanabe 2003a) and activation of the transcription factor CREB in keratinocytes (Kanda \& Watanabe 2003b, 2004). These in turn activate the expression of target genes such as nerve growth factor in macrophages and cyclin D2 and BCL2 in keratinocytes. The anti-apoptotic effects of $E_{2}$-induced $B C L 2$ upregulation are also involved in attenuating hepatic injury caused by trauma-hemorrhage (Hsieh et al. 2007). In breast cancer cells, other signaling pathways may predominate to induce some of the same factors and genes. In ER-negative $\mathrm{SKBr} 3$ breast cancer cells, $\mathrm{E}_{2}$ induces $c$-fos expression through the GPR30/EGFR/MAPK signaling cascade (Maggiolini et al. 2004). $\mathrm{E}_{2}$ and the partial ER antagonist but GPR 30 agonist (see below) hydroxytamoxifen (OHT) both stimulate the expression of $c$-fos and elicit proliferative effects through GPR30 in thyroid and endometrial cancer cells (Vivacqua et al. 2006a,b). In ovarian cancer cells, both $\mathrm{E}_{2}$ and G-1 upregulate numerous estrogen-responsive genes including 
c-fos, pS2, and cyclins A, D1 and E, while other direct ER $\alpha$ target genes such as the progesterone receptor (PR) gene only respond to $E_{2}$ (Albanito et al. 2007). In these ovarian cancer cells, the knockdown of GPR30 or ER $\alpha$ revealed an interesting codependence between these receptors for the induction of $c-f o s$ by G-1 and $\mathrm{E}_{2}$. In contrast, as pointed out above, the upregulation of $c$-fos and, importantly, cell proliferation in response to $\mathrm{E}_{2}$ is solely GPR 30 dependent in a cell context such as the SKBr3 breast cancer cells lacking nuclear ERs (Albanito et al. 2007). The dual dependence on ER $\alpha$ and GPR30 in the case of ovarian cancer cells was further substantiated and extended with the demonstration that the environmental contaminant atrazine stimulates the activation of estrogen target genes and cell proliferation through the GPR30/EGFR/MAPK signal transduction pathway. Although atrazine does not bind to nor activate $\mathrm{ER} \alpha$, this receptor along with GPR 30 is required to elicit the estrogen-like effects (Albanito et al. 2008a). The mouse spermatogonial cell line, GC-1, represents yet another case where both the induction of proliferation and of expression of $c$-fos and cyclin D1 by either $E_{2}$ or G-1 depend on both $\mathrm{ER} \alpha$ and GPR30 (Sirianni et al. 2008). Whereas it is easy to see how $\mathrm{E}_{2}$ signaling could depend on a dual input through both types of receptors, this remains unclear for the GPR 30-specific agonist G-1. The presence of $E R \alpha$, even in its unliganded form, might somehow set the stage for a GPR30-mediated G-1 response.

Most recently, we undertook a systematic characterization of the genomic responses to GPR 30 signaling in breast cancer cells (Pandey et al. 2009). We determined the changes in the gene expression profile of SKBr3 cells elicited by GPR 30 signaling. We discovered that this involves a whole network of transcription factors. Rapid posttranslational activation of a first tier of transcription factors including $S R F, C R E B$, and members of the ETS family promotes the expression of a second wave of transcription factors such as FOS, JUN, $E G R 1, A T F 3, C / E B P \delta$, and $N R 4 A 2$. The activities of many of these are further augmented at the protein level under the effects of GPR 30 signaling, for example by phosphorylation by MAPK. Cells are literally reprogrammed under the effect of this network of transcription factors. Superimposed on these responses, there may be a variety of signaling crosstalk pathways and both negative and positive feedback loops. For example, we found that EGF upregulates GPR30 expression through the EGFR/MAPK pathway in ER-negative breast cancer cells, most likely by promoting the recruitment of the c-FOS-containing transcription factor $A P-1$ to the GPR 30 promoter (Albanito et al. 2008b). Considering that GPR30 signaling uses the EGFR/MAPK pathway, a positive feedback loop is conceivable. This mechanism is also operational for EGF and the related growth factor TGF $\alpha$ in ER $\alpha$-positive breast cancer cells (Vivacqua et al. 2009). The concomitant presence of ER $\alpha$ and GPR30 even allows for a ligand-modulated physical interaction, which provides additional, but still unexplored opportunities for crosstalk. Another intriguing example is that of endometrial and choriocarcinoma cells, where the GPR30-induced production of PIP3 stimulates the activity of the nuclear receptor SF-1 (NR5A1 as listed in the HUGO Database), which in turn enhances the expression of aromatase and thus the production of estrogen and proliferation (Lin et al. 2009). In some cases, the presence of ER $\alpha$ might complicate matters as it has been shown to mediate the repression of GPR30 expression (Lupien et al. 2009). Clearly, there is a lot of room for cell specificity modulating GPR30 signaling.

\section{Role of GPR30 in carcinomas}

As already alluded to above, GPR30 is widely expressed in carcinoma cell lines including ER-positive MCF7 and ER-negative SKBr3 breast cancer cells (Carmeci et al. 1997, Filardo et al. 2000), Hec1A (Vivacqua et al. 2006b) and Hec50 (Revankar et al. 2005) endometrial cancer cells, JEG choriocarcinoma cells (Revankar et al. 2005), BG-1 ovarian cancer cells (Albanito et al. 2007), and thyroid carcinoma cell lines (Vivacqua et al. 2006a). We have shown for many of these that estrogens can stimulate their proliferation through GPR 30 (Vivacqua et al. 2006a,b, Albanito et al. 2007; see also Lin et al. 2009), supporting the notion that GPR30 might contribute to carcinogenesis. Endocrine therapy is often the treatment of choice for breast cancer, including in advanced cases as long as they remain estrogen dependent (Ariazi et al. 2006). Approximately two-thirds of all breast carcinomas express ER $\alpha$, and yet, $25 \%$ of all patients do not respond to tamoxifen therapy (Early Breast Cancer Trialists' Collaborative Group, 2005; see http://www.ctsu.ox.ac.uk/projects/ ebctcg). Even when they initially do, a large fraction of patients eventually develop hormone-refractory cancer lesions, which are characterized by their rapid growth and invasiveness. What exactly promotes this transition remains a matter of intense debate and investigation. The reasons are probably multifactorial, but the discovery of GPR 30 as a new ER puts yet another potential player on the map. The fact that the partial ER antagonist OHT behaves as an agonist for GPR30 (Maggiolini et al. 2004, Thomas et al. 2005, Vivacqua et al. 2006a,b, Henic et al. 2009, Pandey et al. 2009) suggests that conventional anti-estrogenic therapies might in fact stimulate rather than inhibit a subset of tamoxifen-resistant tumors. Whether the activation of GPR30 by estrogens or anti-estrogens indeed contributes to the switch or progression from hormone sensitive to pharmacologically hormoneinsensitive breast cancer still needs to be experimentally corroborated. In this context, an interesting paradox to resolve in future studies is that the GPR30 gene has not emerged in gene expression signatures for aggressive breast cancer (Miller \& Liu 2007) nor has it scored as a hit in functional screens for genes contributing to tamoxifen resistance in breast cancer cells (Meijer et al. 2006, van Agthoven et al. 2009). Given the complexity of these cancers, it is likely that GPR30 will prove to be but one contributing factor and only for a subset of cancers. 
The most extensive survey to date has been performed by Filardo et al. (2006). They examined the presence of $\mathrm{ER} \alpha, \mathrm{PR}$, and GPR30 by immunohistochemistry in 361 breast carcinomas (321 invasive and 40 intraductal tumors) and 12 controls obtained from breast reduction surgery. Normal breast tissue was positive for ER $\alpha$, PR, and GPR 30 . Among the in situ cases, $42 \%$ were GPR 30 positive, $63 \%$ ER $\alpha$ positive, and $45 \%$ PR positive. Among invasive cases, $62 \%$ were GPR 30 positive, $62 \%$ ER $\alpha$ positive, and $40 \%$ PR positive. In $19 \%$ of all cases, neither ER $\alpha$ nor GPR30 were detected, whereas in $43 \%$ of all cases, there was coexpression of both receptors, indicating a significant but incomplete association between ER $\alpha$ and GPR30 expression. A similar association between GPR 30 and PR was not detected. It is noteworthy that the overexpression of GPR30 was significantly associated with tumor size $(>2 \mathrm{~cm})$, the presence of distant metastases, and increased HER-2/neu expression. In contrast, high levels of ER $\alpha$ were inversely correlated with HER-2/neu and tumor size. Thus, these data provide the first evidence regarding the role of GPR30 in human breast carcinoma and suggest that GPR30 overexpression may be a predictor of an aggressive disease.

We recently suggested that evaluating the levels of GPR 30 in combination with those of a set of GPR30 target genes might be more informative to assess the outcome in certain types of cancer (Pandey et al. 2009). We showed that the gene for the connective tissue growth factor (CTGF) is the most strongly induced GPR30 target gene in ER-negative SKBr3 breast cancer cells and that CTGF is necessary for the GPR30-mediated stimulation of proliferation and migration. Whereas CTGF overexpression has been correlated with aggressive behavior of breast cancer cell lines (Kang et al. 2003, Han et al. 2008), CTGF was found to be oppositely correlated with poor outcome in a survey of 122 human breast tumors (Jiang et al. 2004). Yet, elevated CTGF levels have been reported to characterize a number of other types of carcinomas (Bleau et al. 2005, Deng et al. 2007, Liu et al. 2008, Mullis et al. 2008). Hence, further work on this issue and on the question whether the ER $\alpha$ status may influence the effects of CTGF and other target proteins of GPR 30 in breast cancer and other malignancy is clearly warranted.

In contrast to the breast where tamoxifen is usually antiproliferative, epithelial cells of the female reproductive system proliferate upon exposure to either estrogen or tamoxifen (Gottardis et al. 1988). Furthermore, women treated with tamoxifen against breast cancer display an increased incidence of endometrial cancer. While this is consistent with the fact that OHT is an ER $\alpha$ agonist in this tissue (Shang \& Brown 2002, Shang 2006), ER $\alpha-$ independent mechanisms might also be at play. This is supported by the above-mentioned demonstration that GPR30-mediated proliferative stimuli are effective in endometrial and other cancer cell lines. To examine the potential role of GPR 30 in endometrial cancers, Smith et al. (2007) performed a immunohistochemical analysis of $\mathrm{ER} \alpha, \mathrm{PR}, \mathrm{GPR} 30$, EGFR, and the proliferation marker
Ki-67 on tumors from patients with endometrial adenocarcinoma. GPR30 was positively correlated with EGFR but negatively with PR expression. There was a strong positive correlation between ER $\alpha$ and PR expression, whereas GPR30 overexpression occurred more frequently in endometrial carcinomas exhibiting deep myometrial invasion, high-grade, biologically aggressive histological subtypes, and advanced stage. In patients with GPR 30 overexpression, the overall survival rate was significantly worse than that of patients with low GPR30 expression (65.2 and 100\% respectively). Although the sample size was too small for a multivariate analysis, in patients with stage I disease, GPR 30 overexpression was associated with poorer survival rates compared with patients with low GPR30 expression (80 and $100 \%$ respectively). A very recent study by the same authors indicates a similar correlation in ovarian cancer (Smith et al. 2009). Together, these reports support the hypothesis that GPR30 represents an estrogen-responsive receptor that is overexpressed and functionally relevant in high-risk breast, endometrial, and ovarian carcinomas.

\section{Physiological functions}

In addition to the afore-mentioned studies on the potential functions of GPR 30 in cancer and possibly other pathological conditions, the last few years have seen an explosion of studies aimed at uncovering its physiological functions. These advances have been dramatically aided by new genetic and pharmacological tools. Specifically, several mouse knockouts have been reported (Wang et al. 2008a, Haas et al. 2009, Isensee et al. 2009, Mårtensson et al. 2009, Otto et al. 2009), and both a synthetic agonist (Bologa et al. 2006) and antagonist (Dennis et al. 2009) have been identified. The specific agonist G-1 as well as RNA interference to knockdown GPR30 expression has already been widely used in cell- or tissue-based systems (see below).

Initially, with a sex steroid like estrogen, the reproductive tissues naturally attracted a lot of attention. As discussed above, GPR30 does play a role in a subset of carcinomas. Moreover, using the GPR30-specific agonist G-1 and antagonist G15, Prossnitz et al. found that GPR30 mediates part of the proliferative responses of the uterine epithelium to estrogen (Dennis et al. 2009). However, most of the available evidence points to a large variety of functions of GPR 30 in other tissues, which should not come as a surprise in view of the complexity of estrogen functions, even those mediated by the nuclear ERs (Dahlman-Wright et al. 2006, Heldring et al. 2007). At this point, a fixation on reproductive functions (Otto et al. 2008, 2009, Levin 2009) can only hinder progress.

One might have expected that the deletion of the GPR 30 gene in the mouse would lead to unambiguous insights. This is unfortunately not yet the case. The first mouse knockout report by Wang et al. provided evidence for a role of GPR 30 in the sexual dimorphism of immune responses. GPR 30 knockout mice displayed an impaired estrogen-induced 
thymic atrophy and, as a pharmacological correlate, G-1 could induce this response (Wang et al. 2008a). Strangely, the Otto \& Ruiz Noppinger groups could not even detect the expression of GPR30 or of an integrated GPR30-lacZ reporter in the thymus (Isensee et al. 2009, Otto et al. 2009), but did identify some changes in the T-cell compartment (Otto et al. 2009). The GPR30-dependence of these changes was however questioned since they were not sexually dimorphic as one would have expected for a process regulated by a sex steroid. Another study also failed to identify any GPR30-dependence of estrogenic effects on the thymus (Windahl et al. 2009). Whatever the role of GPR30 in the thymus may be, a recent publication adds credence to a link with immunity in demonstrating that GPR30 is required to mediate protective effects of estrogen (and G-1) against an experimental autoimmune encephalomyelitis (Wang et al. 2009). A similar controversy appears to pertain to another phenotype. The Olde \& Leeb-Lundberg groups found that GPR30-deficient female mice had a number of metabolic issues including hyperglycemia, impaired glucose tolerance, reduced bone growth and increased blood pressure, and linked some of these to a role of GPR 30 in $\mathrm{E}_{2}$-induced release of insulin by $\beta$-cells (Mårtensson et al. 2009). A follow-up analysis of the potential role of GPR 30 for longitudinal bone growth showed that GPR30 is not required for the bonesparing effects of estrogen but for basal and estrogenic responses of growth plates (Windahl et al. 2009). In contrast to what was reported from studying this mouse model, no changes in body growth or glucose tolerance were revealed with the GPR30-lacZ mouse, another GPR30-deficient mouse line (Isensee et al. 2009). Yet another independent study seems to confirm that there may at least be metabolic problems in the absence of GPR30. Barton et al. observed an increased body weight and visceral adiposity in GPR 30deficient mice of both sexes, and a GPR30-dependent vascular dilation in response to G-1 (Haas et al. 2009). While these authors logically detected GPR30 expression in fat tissue, others failed to do so and also failed to see differences in obesity and the increased body weight despite the fact that other phenotypic changes were seen in that case (Mårtensson et al. 2009). In appreciating this bewildering complexity, it might be important to take into account differences in genetic background and experimental protocol. It will be critical to control the estrogen environment carefully and therefore to compare sham-operated and ovariectomized animals of the relevant genotypes with and without $\mathrm{E}_{2}$ complementation.

While mouse knockout studies were producing a wealth of (confusing) data, many interesting insights have come from cell or organ culture experiments. RNA interference experiments have been used to demonstrate that GPR 30 is involved in mediating estrogen stimulation of primordial follicle formation in the hamster (Wang et al. 2008b). Although GPR30 can stimulate the proliferation and migration of a subset of carcinomas (see above), the proliferation of osteoblast progenitors (Teplyuk et al. 2008) and a spermatogonial cell line (Sirianni et al. 2008), it is not always stimulatory. For example, the proliferation of human primary bladder cells is inhibited by GPR 30 signaling (Teng et al. 2008) as is the migration of ovarian cancer cells (Henic et al. 2009). In a model for trauma-hemorrhage of the liver, GPR30 was shown to mediate protective effects of $E_{2}$ (Hsieh et al. 2007). In fish, GPR 30 has been found to mediate the $\mathrm{E}_{2}$-induced meiotic arrest of oocytes (Pang et al. 2008, Pang \& Thomas 2009).

A wide range of effects of estrogens in neuronal cells appear to involve GPR 30. These include roles in inhibiting dopamine efflux in PC-12 cells (Alyea et al. 2008) and serotonin signaling in the hypothalamus (Xu et al. 2009), in promoting the depolarization of spinal neurons (Dun et al. 2009), $\mathrm{Ca}^{2+}$ oscillations and release of LHRH from primate neurons (Noel et al. 2009), and mechanical hyperalgesia in nociceptive neurons of rat dorsal root ganglia (Kuhn et al. 2008). Furthermore, there is evidence for additional functions in the hypothalamus as the control of energy homeostasis may involve GPR30 (Qiu et al. 2006), in accordance with the finding that $\mathrm{G}-1$ causes $\mathrm{Ca}^{2+}$ spikes in cultured rat hypothalamic neurons (Brailoiu et al. 2007), and that GPR30 is expressed there and elsewhere in the brain (see, for example Brailoiu et al. 2007, Canonaco et al. 2008, Hazell et al. 2009). This further agrees with a function of GPR30 in the hypothalamic-pituitary axis in regulating the $\mathrm{E}_{2}$-induced prolactin secretion (Lebesgue et al. 2009). An exciting new neurological role of GPR 30 is indicated by a first series of experiments with the GPR30 antagonist G15. G15 blocked the antidepressive effects of both $E_{2}$ and G-1 in a mouse model (Dennis et al. 2009).

\section{Controversies}

Perhaps the most fundamental controversy concerns the question whether GPR30 is an ER at all. This continues to be seriously disputed (Otto et al. 2008, 2009, Levin 2009). While dissent is part of and a driver of the scientific process, one should not forget that positive evidence remains a stronger argument than negative evidence. When some fail to see evidence for GPR 30 signaling in ER-negative breast cancer cells (Pedram et al. 2006), to mention just that biological system, the positive evidence reported by others for breast cancer cells that are devoid of both ER $\alpha$ and ER $\beta$ (for example, Filardo et al. 2000, Maggiolini et al. 2004, Pandey et al. 2009) cannot be ignored. Several groups have shown that cells and/or isolated membranes with GPR30 bind $E_{2}$, whereas cells/membranes without GPR30 do not (Revankar et al. 2005, Thomas et al. 2005, Thomas \& Dong 2006, Filardo et al. 2007, Pang et al. 2008), unless of course they contain membrane-associated nuclear ERs. Similar data have been published for the agonist G-1 (Bologa et al. 2006) and the antagonist G15 (Dennis et al. 2009). Considering all of these and the other data discussed in this review, it seems difficult to argue that GPR30 is not an ER or that it is a mere 'collaborator' (Levin 2009). The ultimate proof might have to 
come from a structural analysis of $\mathrm{E}_{2}$-bound GPR30, but the first structures of any liganded 7TM-GPCRs have only very recently been solved (Rosenbaum et al. 2009).

Intuitively, a 7TM-GPCR like GPR30 might be expected to be localized at the plasma membrane. It turns out that for GPR30 not even the subcellular localization is clear. Prossnitz et al. provided seemingly compelling evidence for a localization of both tagged exogenous and endogenous GPR30 at the endoplasmic reticulum (Revankar et al. 2005). This is supported by a very recent report from another group demonstrating the colocalization of GPR30 with calnexin (Lin et al. 2009). According to others, GPR30, at least in oxytocin neurons, is mainly localized in the Golgi (Sakamoto et al. 2007). Other authors found it on the plasma membrane of primary neurons but intracellularly in some transfection experiments (Funakoshi et al. 2006). Filardo \& Thomas and their colleagues carefully revisited this issue with a variety of staining and biochemical approaches. They also showed activation of GPR30 signaling with $\mathrm{E}_{2}$ coupled to carrier proteins such as BSA that should have prevented access to intracellular GPR30 (Filardo et al. 2007; see also Thomas et al. 2005, Pang et al. 2008). Likewise, the afore-mentioned LHRH release can also be stimulated with a cell-impermeable estrogen dendrimer conjugate (Noel et al. 2009). Whether the demonstration that FITC-labeled $\mathrm{E}_{2}-\mathrm{BSA}$ rapidly gains access to the membrane of the endoplasmic reticulum in a GPR30dependent manner suggesting shuttling of GPR30 (Wang et al. 2008b) tilts the balance one way or another is highly unlikely. It cannot be excluded that the fluorochrome FITC altered the membrane tropism of $\mathrm{E}_{2}-\mathrm{BSA}$. At the very least, all of these groups agree that GPR 30 is a membrane-bound ER. It seems that novel tools or approaches might need to be developed to sort out where the bulk of GPR30 resides and where a possibly smaller subset of functional molecules act. It is of course not impossible that the answer may depend on cell type, and even for a given cell type, on additional intra- and extracellular factors.

The potential role of GPR30 in the reproductive system has been construed as a problem or controversy. As discussed above, while GPR 30 may play some role in primary follicle formation, oocyte maturation, the proliferation of the uterine epithelium, and pathologically in some carcinomas of the breast, endometrium, and ovary, its main functions might lie outside of the reproductive system. Some of these are likely to be linked to sex-specific functions of estrogen, whereas others will not. Some will be complementary to those of ER $\alpha$ and $\operatorname{ER} \beta$, others will not.

Another 'issue' is the pharmacology of GPR 30. It is fair to say that it remains extremely poorly understood. $\mathrm{E}_{2}$ and the specific ligand G-1 are undoubtedly agonists. So are some environmental and plant-derived estrogens (Maggiolini et al. 2004, Thomas \& Dong 2006, Vivacqua et al. 2006a), the partial ER antagonist OHT (see above), and the anti-estrogen ICI 182780 in some settings (Filardo et al. 2000, Thomas et al. 2005, Henic et al. 2009, Pang \& Thomas 2009, Quinn et al. 2009) but not all (Pandey et al. 2009). A related issue is that of the concentrations required to obtain a full response. While we have typically used $\mu \mathrm{M}$ concentrations with carcinoma cells and argued for OHT that this is in a therapeutically meaningful range (see Pandey et al. 2009), those working with $\mathrm{E}_{2}$ and G-1 in other biological systems have observed binding affinities and half-maximal responses in the nanomolar or subnanomolar range (Revankar et al. 2005, Thomas et al. 2005, Thomas \& Dong 2006, Filardo et al. 2007, Pang et al. 2008). To what extent cell-type differences exist and whether the type of assay, for example the induction of a $\mathrm{Ca}^{2+}$-influx within seconds to minutes or of gene expression changes within hours, influences the dose-response for different ligands remains to be more carefully explored.

\section{Future}

With the discovery of GPR 30 as a new ER, the estrogen field has opened a pandora's box whose full impact has yet to be appreciated. We are really only at the beginning of deciphering the contributions of GPR30 to physiological and pathological estrogen responses. As argued above, its main function may not be in the reproductive system but in some of those other instances where the sex steroid estrogen conditions cells and tissues. The biological functions of GPR 30 will eventually emerge most clearly from studies that use a combination of genetic (for example, mouse knockouts in controlled genetic backgrounds, RNA interference, gene transfer), pharmacological (synthetic agonists and antagonists) and biochemical (highly specific and validated antibodies and other types of probes) tools. A connection of GPR30 to diseases such as cancer has already tentatively emerged, but larger sample sizes with more measured parameters and patient follow-up are needed to clarify it.

Considering the available biological and pharmacological data, $E_{2}$ is a very likely physiological ligand, but the establishment of a more comprehensive pharmacological spectrum may reveal others. It is even conceivable that $\mathrm{E}_{2}$ is not the main physiological ligand. Indeed, in view of the conceptual and practical difficulties of determining what the physiological ligand for any GPCR is, one might be well advised to keep an open mind about it. Moreover, it appears that GPR30 is a target for estrogenic endocrine disruptors. The consequences of this will also need to be evaluated as the biological functions of GPR30 are filled in.

Finally, much of the cell and molecular biology of GPR 30 remains uncharted territory. How does it go to the membrane (and which membrane after all)? What defines GPR30 as an ER at the molecular level? What are its structural and functional relationships to its next kins in the GPCR family? To this date, no structure-function studies have been done at all. Although human and mouse GPR30 are 87\% identical, the remaining $13 \%$ could potentially generate considerable species differences in GPR30 function and pharmacology. This should be taken into account in interpreting results from animal models. 


\section{Declaration of interest}

The authors declare that there is no conflict of interest that could be perceived as prejudicing the impartiality of the research reported.

\section{Funding}

Work in MM's laboratory was supported by the 'Associazione Italiana per la Ricerca sul Cancro (AIRC)', the 'Ministero dell'Università e Ricerca Scientifica e Tecnologica', and the 'Regione Calabria and Provincia di Cosenza'. Work in DP's laboratory was supported by the Canton de Genève, the Swiss National Science Foundation, and the Fondation Medic.

\section{References}

van Agthoven T, Sieuwerts AM, Meijer-van Gelder ME, Look MP, Smid M, Veldscholte J, Sleijfer S, Foekens JA \& Dorssers LC 2009 Relevance of breast cancer antiestrogen resistance genes in human breast cancer progression and tamoxifen resistance. Journal of Clinical Oncology 27 542-549.

Albanito L, Madeo A, Lappano R, Vivacqua A, Rago V, Carpino A, Oprea TI, Prossnitz ER, Musti AM, Ando S et al. 2007 G protein-coupled receptor 30 (GPR 30) mediates gene expression changes and growth response to $17 \beta$-estradiol and selective GPR30 ligand G-1 in ovarian cancer cells. Cancer Research 67 1859-1866.

Albanito L, Lappano R, Madeo A, Chimento A, Prossnitz ER, Cappello AR, Dolce V, Abonante S, Pezzi V \& Maggiolini M 2008a G-protein-coupled receptor 30 and estrogen receptor-alpha are involved in the proliferative effects induced by atrazine in ovarian cancer cells. Environmental Health Perspectives 116 1648-1655.

Albanito L, Sisci D, Aquila S, Brunelli E, Vivacqua A, Madeo A, Lappano R, Pandey DP, Picard D, Mauro L et al. 2008b EGF induces GPR30 expression in estrogen receptor-negative breast cancer cells. Endocrinology 149 3799-3808.

Alyea RA, Laurence SE, Kim SH, Katzenellenbogen BS, Katzenellenbogen JA \& Watson CS 2008 The roles of membrane estrogen receptor subtypes in modulating dopamine transporters in PC-12 cells. Journal of Neurochemistry 106 1525-1533.

Ariazi EA, Ariazi JL, Cordera F \& Jordan VC 2006 Estrogen receptors as therapeutic targets in breast cancer. Current Topics in Medicinal Chemistry 6 181-202.

Aronica SM, Kraus WL \& Katzenellenbogen BS 1994 Estrogen action via the cAMP signaling pathway: stimulation of adenylate cyclase and cAMP-regulated gene transcription. PNAS 91 8517-8521.

Bleau AM, Planque N \& Perbal B 2005 CCN proteins and cancer: two to tango. Frontiers in Bioscience 10 998-1009.

Bologa CG, Revankar CM, Young SM, Edwards BS, Arterburn JB, Kiselyov AS, Parker MA, Tkachenko SE, Savchuck NP, Sklar LA et al. 2006 Virtual and biomolecular screening converge on a selective agonist for GPR30. Nature Chemical Biology 2 207-212.

Bonini JA, Anderson SM \& Steiner DF 1997 Molecular cloning and tissue expression of a novel orphan $\mathrm{G}$ protein-coupled receptor from rat lung. Biochemical and Biophysical Research Communications 234 190-193.

Brailoiu E, Dun SL, Brailoiu GC, Mizuo K, Sklar LA, Oprea TI, Prossnitz ER \& Dun NJ 2007 Distribution and characterization of estrogen receptor G protein-coupled receptor 30 in the rat central nervous system. Journal of Endocrinology 193 311-321.

Canonaco M, Giusi G, Madeo A, Facciolo RM, Lappano R, Canonaco A \& Maggiolini M 2008 A sexually dimorphic distribution pattern of the novel estrogen receptor G-protein-coupled receptor 30 in some brain areas of the hamster. Journal of Endocrinology 196 131-138.
Carmeci C, Thompson DA, Ring HZ, Francke U \& Weigel RJ 1997 Identification of a gene (GPR30) with homology to the G-protein-coupled receptor superfamily associated with estrogen receptor expression in breast cancer. Genomics 45 607-617.

Dahlman-Wright K, Cavailles V, Fuqua SA, Jordan VC, Katzenellenbogen JA, Korach KS, Maggi A, Muramatsu M, Parker MG \& Gustafsson JA 2006 International Union of Pharmacology. LXIV. Estrogen receptors. Pharmacological Reviews 58 773-781.

Deng YZ, Chen PP, Wang Y, Yin D, Koeffler HP, Li B, Tong XJ \& Xie D 2007 Connective tissue growth factor is overexpressed in esophageal squamous cell carcinoma and promotes tumorigenicity through betacatenin-T-cell factor/Lef signaling. Journal of Biological Chemistry 282 36571-36581.

Dennis MK, Burai R, Ramesh C, Petrie WK, Alcon SN, Nayak TK, Bologa CG, Leitao A, Brailoiu E, Deliu E et al. 2009 In vivo effects of a GPR30 antagonist. Nature Chemical Biology 5 421-427.

Dun SL, Brailoiu GC, Gao X, Brailoiu E, Arterburn JB, Prossnitz ER, Oprea TI \& Dun NJ 2009 Expression of estrogen receptor GPR30 in the rat spinal cord and in autonomic and sensory ganglia. Journal of Neuroscience Research 87 1610-1619.

Feng Y \& Gregor P 1997 Cloning of a novel member of the G proteincoupled receptor family related to peptide receptors. Biochemical and Biophysical Research Communications 231 651-654.

Filardo EJ, Quinn JA, Bland KI \& Frackelton AR Jr 2000 Estrogen-induced activation of Erk-1 and Erk-2 requires the G protein-coupled receptor homolog, GPR30, and occurs via trans-activation of the epidermal growth factor receptor through release of HB-EGF. Molecular Endocrinology 14 1649-1660.

Filardo EJ, Quinn JA, Frackelton AR Jr \& Bland KI 2002 Estrogen action via the $\mathrm{G}$ protein-coupled receptor, GPR 30: stimulation of adenylyl cyclase and cAMP-mediated attenuation of the epidermal growth factor receptorto-MAPK signaling axis. Molecular Endocrinology 16 70-84.

Filardo EJ, Graeber CT, Quinn JA, Resnick MB, Giri D, DeLellis RA, Steinhoff MM \& Sabo E 2006 Distribution of GPR 30, a seven membranespanning estrogen receptor, in primary breast cancer and its association with clinicopathologic determinants of tumor progression. Clinical Cancer Research 12 6359-6366.

Filardo E, Quinn J, Pang Y, Graeber C, Shaw S, Dong J \& Thomas P 2007 Activation of the novel estrogen receptor $G$ protein-coupled receptor 30 (GPR30) at the plasma membrane. Endocrinology 148 3236-3245.

Filardo EJ, Quinn JA \& Sabo E 2008 Association of the membrane estrogen receptor, GPR 30, with breast tumor metastasis and transactivation of the epidermal growth factor receptor. Steroids 73 870-873.

Funakoshi T, Yanai A, Shinoda K, Kawano MM \& Mizukami Y 2006 $\mathrm{G}$ protein-coupled receptor 30 is an estrogen receptor in the plasma membrane. Biochemical and Biophysical Research Communications 346 904-910.

Gottardis MM, Robinson SP, Satyaswaroop PG \& Jordan VC 1988 Contrasting actions of tamoxifen on endometrial and breast tumor growth in the athymic mouse. Cancer Research 48 812-815.

Haas E, Bhattacharya I, Brailoiu E, Damjanovic M, Brailoiu GC, Gao X, Mueller-Guerre L, Marjon NA, Gut A, Minotti R et al. 2009 Regulatory role of $\mathrm{G}$ protein-coupled estrogen receptor for vascular function and obesity. Circulation Research 104 288-291.

Han HJ, Russo J, Kohwi Y \& Kohwi-Shigematsu T 2008 SATB1 reprogrammes gene expression to promote breast tumour growth and metastasis. Nature 452 187-193.

Hazell G, Yao S, Roper J, Prossnitz E, O’Carroll AM \& Lolait S 2009 Localisation of GPR 30, a novel G protein-coupled oestrogen receptor, suggests multiple functions in rodent brain and peripheral tissues. Journal of Endocrinology 202 223-236.

Heldring N, Pike A, Andersson S, Matthews J, Cheng G, Hartman J, Tujague M, Strom A, Treuter E, Warner M et al. 2007 Estrogen receptors: how do they signal and what are their targets. Physiological Reviews 87 905-931.

Henic E, Noskova V, Høyer-Hansen G, Hansson S \& Casslén B 2009 Estradiol attenuates EGF-induced rapid uPAR mobilization and cell migration via the G-protein-coupled receptor 30 in ovarian cancer cells. International Journal of Gynecological Cancer 19 214-222. 
Hsieh YC, Yu HP, Frink M, Suzuki T, Choudhry MA, Schwacha MG \& Chaudry IH 2007 G protein-coupled receptor 30-dependent protein kinase A pathway is critical in nongenomic effects of estrogen in attenuating liver injury after trauma-hemorrhage. American Journal of Pathology 170 1210-1218.

Isensee J, Meoli L, Zazzu V, Nabzdyk C, Witt H, Soewarto D, Effertz K, Fuchs H, Gailus-Durner V, Busch D et al. 2009 Expression pattern of G protein-coupled receptor 30 in LacZ reporter mice. Endocrinology $\mathbf{1 5 0}$ 1722-1730.

Jiang WG, Watkins G, Fodstad O, Douglas-Jones A, Mokbel K \& Mansel RE 2004 Differential expression of the CCN family members Cyr61, CTGF and Nov in human breast cancer. Endocrine-Related Cancer 11 781-791.

Kanda N \& Watanabe S 2003a 17 $\beta$-Estradiol enhances the production of nerve growth factor in THP-1-derived macrophages or peripheral blood monocyte-derived macrophages. Journal of Investigative Dermatology 121 $771-780$.

Kanda N \& Watanabe S $2003 b$ 17 $\beta$-Estradiol inhibits oxidative stress-induced apoptosis in keratinocytes by promoting Bcl-2 expression. Journal of Investigative Dermatology 121 1500-1509.

Kanda N \& Watanabe S 2004 17ß-Estradiol stimulates the growth of human keratinocytes by inducing cyclin D2 expression. Journal of Investigative Dermatology 123 319-328.

Kang Y, Siegel PM, Shu W, Drobnjak M, Kakonen SM, Cordon-Cardo C, Guise TA \& Massagué J 2003 A multigenic program mediating breast cancer metastasis to bone. Cancer Cell 3 537-549.

Kimura M, Mizukami Y, Miura T, Fujimoto K, Kobayashi S \& Matsuzaki M 2001 Orphan G protein-coupled receptor, GPR 41, induces apoptosis via a p53/Bax pathway during ischemic hypoxia and reoxygenation. Journal of Biological Chemistry 276 26453-26460.

Kuhn J, Dina OA, Goswami C, Suckow V, Levine JD \& Hucho T 2008 GPR30 estrogen receptor agonists induce mechanical hyperalgesia in the rat. European Journal of Neuroscience 27 1700-1709.

Kuiper GG, Enmark E, Pelto Huikko M, Nilsson S \& Gustafsson J-Å 1996 Cloning of a novel receptor expressed in rat prostate and ovary. PNAS 93 5925-5930.

Lebesgue D, Reyna-Neyra A, Huang X \& Etgen AM 2009 GPR30 differentially regulates short latency responses of luteinising hormone and prolactin secretion to oestradiol. Journal of Neuroendocrinology 21 743-752.

Levin ER 2009 G protein-coupled receptor 30: estrogen receptor or collaborator? Endocrinology 150 1563-1565.

Lin BC, Suzawa M, Blind RD, Tobias SC, Bulun SE, Scanlan TS \& Ingraham HA 2009 Stimulating the GPR30 estrogen receptor with a novel tamoxifen analogue activates SF-1 and promotes endometrial cell proliferation. Cancer Research $695415-5423$.

Liu LY, Han YC, Wu SH \& Lv ZH 2008 Expression of connective tissue growth factor in tumor tissues is an independent predictor of poor prognosis in patients with gastric cancer. World Journal of Gastroenterology 14 2110-2114.

Lupien M, Eeckhoute J, Meyer CA, Krum SA, Rhodes DR, Liu XS \& Brown M 2009 Coactivator function defines the active estrogen receptor $\alpha$ cistrome. Molecular and Cellular Biology 29 3413-3423.

Maggiolini M, Vivacqua A, Fasanella G, Recchia AG, Sisci D, Pezzi V, Montanaro D, Musti AM, Picard D \& Andò S 2004 The G protein-coupled receptor GPR 30 mediates $c$-fos up-regulation by $17 \beta$-estradiol and phytoestrogens in breast cancer cells. Journal of Biological Chemistry 279 27009-27016.

Mårtensson UE, Salehi SA, Windahl S, Gomez MF, Swärd K, DaszkiewiczNilsson J, Wendt A, Andersson N, Hellstrand P, Grände PO et al. 2009 Deletion of the $\mathrm{G}$ protein-coupled receptor 30 impairs glucose tolerance, reduces bone growth, increases blood pressure, and eliminates estradiolstimulated insulin release in female mice. Endocrinology 150 687-698.

Meijer D, van Agthoven T, Bosma PT, Nooter K \& Dorssers LC 2006 Functional screen for genes responsible for tamoxifen resistance in human breast cancer cells. Molecular Cancer Research 4 379-386.

Migliaccio A, Di Domenico M, Castoria G, de Falco A, Bontempo P, Nola E \& Auricchio F 1996 Tyrosine kinase/p21 ${ }^{\text {ras }} /$ MAP-kinase pathway activation by estradiol-receptor complex in MCF-7 cells. EMBO Journal 15 1292-1300.
Miller LD \& Liu ET 2007 Expression genomics in breast cancer research: microarrays at the crossroads of biology and medicine. Breast Cancer Research 9206.

Mullis TC, Tang X \& Chong KT 2008 Expression of connective tissue growth factor $(\mathrm{CTGF} / \mathrm{CCN} 2)$ in head and neck squamous cell carcinoma. Journal of Clinical Pathology 61 606-610.

Noel SD, Keen KL, Baumann DI, Filardo EJ \& Terasawa E 2009 Involvement of $\mathrm{G}$ protein-coupled receptor 30 (GPR30) in rapid action of estrogen in primate LHRH neurons. Molecular Endocrinology 23 349-359.

Otto C, Rohde-Schulz B, Schwarz G, Fuchs I, Klewer M, Brittain D, Langer G, Bader B, Prelle K, Nubbemeyer R et al. 2008 G protein-coupled receptor 30 localizes to the endoplasmic reticulum and is not activated by estradiol. Endocrinology 149 4846-4856.

Otto C, Fuchs I, Kauselmann G, Kern H, Zevnik B, Andreasen P, Schwarz G, Altmann H, Klewer M, Schoor M et al. 2009 GPR30 does not mediate estrogenic responses in reproductive organs in mice. Biology of Reproduction 80 34-41.

Pandey DP, Lappano R, Albanito L, Madeo A, Maggiolini M \& Picard D 2009 Estrogenic GPR 30 signaling induces proliferation and migration of breast cancer cells through CTGF. EMBO Journal 28 523-532.

Pang Y \& Thomas P 2009 Involvement of estradiol-17beta and its membrane receptor, G protein coupled receptor 30 (GPR30) in regulation of oocyte maturation in zebrafish, Danio rario. General and Comparative Endocrinology 161 58-61.

Pang Y, Dong J \& Thomas P 2008 Estrogen signaling characteristics of Atlantic croaker G protein-coupled receptor 30 (GPR30) and evidence it is involved in maintenance of oocyte meiotic arrest. Endocrinology 149 3410-3426.

Pedram A, Razandi M \& Levin ER 2006 Nature of functional estrogen receptors at the plasma membrane. Molecular Endocrinology 20 1996-2009.

Prossnitz ER \& Maggiolini M 2009 Mechanisms of estrogen signaling and gene expression via GPR30. Molecular and Cellular Endocrinology 308 32-38.

Prossnitz ER, Arterburn JB, Smith HO, Oprea TI, Sklar LA \& Hathaway HJ 2008 Estrogen signaling through the transmembrane $G$ protein-coupled receptor GPR30. Annual Review of Physiology 70 165-190.

Qiu J, Bosch MA, Tobias SC, Krust A, Graham SM, Murphy SJ, Korach KS, Chambon P, Scanlan TS, Ronnekleiv OK et al. 2006 A G-protein-coupled estrogen receptor is involved in hypothalamic control of energy homeostasis. Journal of Neuroscience 26 5649-5655.

Quinn JA, Graeber CT, Frackelton AR Jr, Kim M, Schwarzbauer JE \& Filardo EJ 2009 Coordinate regulation of estrogen-mediated fibronectin matrix assembly and epidermal growth factor receptor transactivation by the G-protein-coupled receptor, GPR30. Molecular Endocrinology 23 1052-1064

Revankar CM, Cimino DF, Sklar LA, Arterburn JB \& Prossnitz ER 2005 A transmembrane intracellular estrogen receptor mediates rapid cell signaling. Science 307 1625-1630.

Rosenbaum DM, Rasmussen SG \& Kobilka BK 2009 The structure and function of G-protein-coupled receptors. Nature 459 356-363.

Sakamoto H, Matsuda K, Hosokawa K, Nishi M, Morris JF, Prossnitz ER \& Kawata M 2007 Expression of G protein-coupled receptor-30, a G protein-coupled membrane estrogen receptor, in oxytocin neurons of the rat paraventricular and supraoptic nuclei. Endocrinology 148 5842-5850.

Shang Y 2006 Molecular mechanisms of oestrogen and SERMs in endometrial carcinogenesis. Nature Reviews. Cancer 6 360-368.

Shang Y \& Brown M 2002 Molecular determinants for the tissue specificity of SERMs. Science 295 2465-2468.

Sirianni R, Chimento A, Ruggiero C, De Luca A, Lappano R, Andò S, Maggiolini M \& Pezzi V 2008 The novel estrogen receptor GPR30 mediates the proliferative effects induced by $17 \beta$-estradiol on mouse spermatogonial GC-1 cell line. Endocrinology 149 5043-5051.

Smith HO, Leslie KK, Singh M, Qualls CR, Revankar CM, Joste NE \& Prossnitz ER 2007 GPR 30: a novel indicator of poor survival for endometrial carcinoma. American Journal of Obstetrics and Gynecology 196 386.e1-386.e9. 
Smith HO, Arias-Pulido H, Kuo DY, Howard T, Qualls CR, Lee SJ, Verschraegen CF, Hathaway HJ, Joste NE \& Prossnitz ER 2009 GPR 30 predicts poor survival for ovarian cancer. Gynecologic Oncology 114 465-471.

Takada Y, Kato C, Kondo S, Korenaga R \& Ando J 1997 Cloning of cDNAs encoding $\mathrm{G}$ protein-coupled receptor expressed in human endothelial cells exposed to fluid shear stress. Biochemical and Biophysical Research Communications 240 737-741.

Teng J, Wang ZY, Prossnitz ER \& Bjorling DE 2008 The G protein-coupled receptor GPR 30 inhibits human urothelial cell proliferation. Endocrinology 149 4024-4034.

Teplyuk NM, Galindo M, Teplyuk VI, Pratap J, Young DW, Lapointe D, Javed A, Stein JL, Lian JB, Stein GS et al. 2008 Runx2 regulates G proteincoupled signaling pathways to control growth of osteoblast progenitors. Journal of Biological Chemistry 283 27585-27597.

Thomas P \& Dong J 2006 Binding and activation of the seven-transmembrane estrogen receptor GPR30 by environmental estrogens: a potential novel mechanism of endocrine disruption. Journal of Steroid Biochemistry and Molecular Biology 102 175-179.

Thomas P, Pang Y, Filardo EJ \& Dong J 2005 Identity of an estrogen membrane receptor coupled to a $G$ protein in human breast cancer cells. Endocrinology 146 624-632.

Vivacqua A, Bonofiglio D, Albanito L, Madeo A, Rago V, Carpino A, Musti AM, Picard D, Andò S \& Maggiolini M 2006a 17ß-Estradiol, genistein and 4-hydroxytamoxifen induce the proliferation of thyroid cancer cells through the G protein-coupled receptor GPR30. Molecular Pharmacology 70 1414-1423.

Vivacqua A, Bonofiglio D, Recchia AG, Musti AM, Picard D, Andò S \& Maggiolini M 2006b The G protein-coupled receptor GPR30 mediates the proliferative effects induced by $17 \beta$-estradiol and hydroxytamoxifen in endometrial cancer cells. Molecular Endocrinology 20 631-646.
Vivacqua A, Lappano R, De Marco P, Sisci D, Aquila S, De Amicis F, Fuqua SA, Andò S \& Maggiolini M 2009 G protein-coupled receptor 30 expression is up-regulated by EGF and TGF $\alpha$ in estrogen receptor $\alpha$ positive cancer cells. Molecular Endocrinology 23 1815-1826.

Wang C, Dehghani B, Magrisso IJ, Rick EA, Bonhomme E, Cody DB, Elenich LA, Subramanian S, Murphy SJ, Kelly MJ et al. 2008a GPR30 contributes to estrogen-induced thymic atrophy. Molecular Endocrinology 22 636-648.

Wang C, Prossnitz ER \& Roy SK 2008b G protein-coupled receptor 30 expression is required for estrogen stimulation of primordial follicle formation in the hamster ovary. Endocrinology 149 4452-4461.

Wang C, Dehghani B, Li Y, Kaler LJ, Proctor T, Vandenbark AA \& Offner H 2009 Membrane estrogen receptor regulates experimental autoimmune encephalomyelitis through up-regulation of programmed death 1. Journal of Immunology 182 3294-3303.

Windahl SH, Andersson N, Chagin AS, Mårtensson UE, Carlsten H, Olde B, Swanson C, Movérare-Skrtic S, Sävendahl L, Lagerquist MK et al. 2009 The role of the G protein-coupled receptor GPR30 in the effects of estrogen in ovariectomized mice. American Journal of Physiology. Endocrinology and Metabolism 296 E490-E496.

Xu H, Qin S, Carrasco GA, Dai Y, Filardo EJ, Prossnitz ER, Battaglia G, Doncarlos LL \& Muma NA 2009 Extra-nuclear estrogen receptor GPR30 regulates serotonin function in rat hypothalamus. Neuroscience 158 1599-1607.

Received in final form 21 August 2009

Accepted 18 September 2009

Made available online as an Accepted Preprint 18 September 2009 